\title{
Analysis of the Impact of Digital Technologies on Chinese Economic Growth
}

\author{
Alida Magakam Tchamekwen \\ School of Finance and Economics, Jiangsu University China \\ No. 301 Xuefu Road, Zhenjiang, Jiangsu, P.R.China 212013 \\ Zhao Xicang \\ No. 301 Xuefu Road, Zhenjiang, Jiangsu, P.R.China 212013
}

\begin{abstract}
This study aims to analyze the impact of digital technologies on the Chinese economic growth from 2013 to 2018 . The research takes into account five digital technologies namely cloud computing, artificial intelligence, robotics, big data and the internet of things. In order to evaluate the role of each of the five digital technologies on china economy, we run a linear regression model of each of them with the country GDP. the results reveal that despite difference in their level of significance, Cloud Computing, Artificial Intelligence, Robotics, Internet of Things and Big Data have a positive significant impact on the country GDP.
\end{abstract}

Keywords: Digital technologies, cloud computing, artificial intelligence, robotics, big data, internet of things, Chinese economic growth.

DOI: $10.7176 / \mathrm{JESD} / 10-8-15$

Publication date: April $30^{\text {th }} 2019$

\section{Introduction.}

The term digital economy was first coined by Don Tapscott in 1995 in his book The Digital Economy: Promise and Peril in the Age of Networked Intelligence. Since then, the term Digital Economy has been differently defined by scholars, business players, economists and researchers. Founder of the Massachusetts Institute of Technology's Media Lab and author of the book Being Digital Nicholas Negroponte described the digital economy as using "bits instead of atoms." Many authors tend to define digital economy as being solely related to information and communications technologies (ICT) .For example Margaret Rouse first posed that the digital economy is the worldwide network of economic activities, commercial transactions and professional interactions that are enabled by information and communications technologies (ICT).Besides some studies claim that Digital economy could be summed up as the economy based on internet transactions and activities, this idea led to terms such: the internet economy, the web economy or the new economy. But all these definitions have deep limitations since the Digital Economy goes far beyond the sole concept of bits, internet connectivity and ICT. Indeed, the Digital Economy implies larger application starting from bits, internet connectivity, and ICT technologies to many other digital technologies. The Digital Economy goes deeper again with the implications of digitalizations in business and economic practices. In fact business and economic activities today have to combine Digital technologies and Digital thinking in order to be more efficient and more productive. Countries of the world are setting digital economy as a priority due to its fast growth without considerable inflation experience. Governments and private sector are henceforth aware of the tremendous role that digital economy plays through digital technologies production and usage. The impact of the digital economy on economic growth and productivity gave rise to a large number of debates and publications in the late 1990s and early 2000s. The fast diffusion of digital technologies has undoubtedly contributed to the increase in productivity, in the United States in 2016 the digital economy value reached up $\$ 11000$ billion representing 59.2\% share in the GDP. In Japan, the 2016 digital economy numbered at $\$ 2300$ billion and accounted for $45.9 \%$ of the country GDP while European economies since 2000 are experiencing a slow growth of digital economy due to a lower capacity to adopt and exploit the digital technologies .China as many developed and developing countries has embraced the trend of digital technologies to boost its economic growth. During the fourth world internet congress in Wuzhen from 3rd to 5th December 2017 the Chinese President Xi Jinping expressed China's desire to promote its digital economy. China's digital economy has boomed in recent years with the fast lade in development and use of digital technologies such cloud computing, big data, artificial intelligence and the Internet of things. Indeed, In 2016, China's digital economy reached 22580 billion Yuan, with a growth rate of 21.2 percent and a 30.3 percent share of GDP. The digital economy in its whole concept and consideration is definitely a key engine of growth, but the question still remaining is the one about how each of the digital technologies analyzed separately impacts the Chinese GDP growth.

This study contributes to the existing literature as it considers all the digital technologies rather than focusing on only one to explain the impact of the digital economy on the GDP of China. Further, our work more than analyzing the effect of the digital technologies on the economic growth provides insights of the degree of significance of each of these digital technologies on the GDP. 
This work is structured as following: the literature review will address the effects of digital technologies at the macro and micro level, the second part details the methodology used in the econometric analysis, Then comes the last section which providing an exhibit of the results, interpretation and discussion, followed by our conclusion.

\section{Literature review}

\subsection{Cloud computing and economic performance}

Cloud computing can be defined as a type of internet based computing model in which different features such as applications, storage and servers are consigned to an organization's computers and devices through the Internet. Thus cloud computing is a set of hardware, networks, storage, services and interfaces combined to deliver aspects of computing as a service based on user demand (Judith H, Robin B, Marcia K, Fern H. 2009).Cloud computing could also be simply defined as the procedure of storing and accessing data and applications over the Internet, instead of the user's computer hard drive(Griffith 2013). From a technical perspective, the structure of the cloud is made of five essential characteristics (On-demand self service, Broad network access, Resource pooling, Rapid elasticity, Measured service) three service models (Infrastructure-as-a-service, Platform-as-a-service, Softwareas-a-service) and four deployment models (Public cloud, Private cloud, Hybrid cloud, Community cloud). Leila Serhan (2015) in her studies finds that cloud technology is an engine of economic growth through the enhancement of mobile productivity and big data. She outlines that cloud computing besides being a solution for private businesses lacking capital also allows organizations of the public sector to improve their services. The new business model created by cloud computing allows companies to enter new markets and to improve their relationship with partners and customers. Etro.F (2009) pointed that the adoption of cloud computing business model in Europe boosted countries competitiveness and economic development. The Centre for Economics and Business Research Ltd in some analysis found that powerful European economies are experiencing economic growth thanks to cloud computing. Indeed the center outlines that cloud computing counted for $1.50 \%$ GDP of France, $1.59 \%$ GDP of Germany, and $1.26 \%$ GDP of the UK. Focusing on the case of china, Han Qi (2015) suggested that China should strengthen cloud computing planning leadership, accelerate the development of autonomous and controllable cloud computing technologies and products, cloud contributes to establish a better business environment since boundaries among industries are broken allowing them to establish deeper corporation and resources exchange. The cloud industry in fostering innovation through knowledge sharing. Its effect on economic growth is visible through its wide application to diverse fields such as energy system, transportation, financial system, education and public health. Cloud computing presents opportunities for nation's growth by offering new economic benefits through new business model in line with cost reduction since data and other information are moved to the cloud making it unnecessary to spend money into hardware, software servers and storage. Enterprises can thus take advantage of cloud computing model flexible cost (Filiopoulou, E., Mitropoulou, P. and Michalakelis, C. 2014). Cloud computing is assessed as a key driver of enterprise productivity and efficiency without the need to deplore high investments (Marston, S., Li, Z., Bandyopadhyay, S., Zhang, J. and Ghalsasi. A.2011).

Clouds computing also boost job creation and entrepreneurship since new firms are created in the field due to the idea that the cloud industry generates high profits for cloud providers (Konstantinos, Katsantonis \& Mitropoulou, Persefoni \& Filiopoulou, Evangelia \& Michalakelis, Christos \& Nikolaidou, Mara, 2015). In contrast there are worries about the fact that cloud computing could lead to the limitation of employment or suppression of existing job Azarnik A, Shayan J, Alizadeh M, Karamizadeh S.2012)

\subsection{Artificial Intelligence and Robotics}

Studies on the economic impact of artificial intelligence are tremendously gaining attention. Artificial intelligence also known as machine intelligence is defined as the stimulation of human intelligence behavior into computer systems while robotics deals with the creation of robots able to autonomously and semi-autonomously carry out series of actions. The existing literature tends to set that artificial intelligence and robotics positively affect economic growth through productivity and employment.

Increasingly number of economists are enthusiastic about the potentiality of artificial intelligence and robotics for economic productivity, indeed artificial intelligence and robotics are key engine of innovation which leads to productivity growth (Cockburn et al.,forthcoming.2017).In their researches, Graetz and Guy Michaels (2011) analyzed the impact of robots on 14 industries across 17 developed countries from 1993-2007 they found that industrial robots are drivers of labor productivity, total factor productivity and wages. They also found that activities related to robotics increased nearly $0.4 \%$ to the GDP of 17 countries. According to a McKinsey's report of 2017, artificial intelligence increases the Chinese economic productivity by $0.8-1.4$ each year. Artificial intelligence and robotics could contribute up to \$ 15 trillion to the global GDP (John Hwaskworth, Richard Berriman and Saloni Goel.2018).

As artificial intelligence and robotics increase productivity they have both negative and positive impacts on labor (Jason Furman and Robert Seamans.2018). Bao Chunlei focused on the impact of artificial intelligence 
development on employment in China; he found that artificial intelligence has both substitution and creative effect on employment. John Hwaskworth, Richard Berriman and Saloni Goel (2018) predict that by 2030 there could be $38 \%$ risk of automation in the US, $21 \%$ in Japan and 35\% in Germany. McKinsey found that nearly half of the global activities could experience the substitute effect of AI and robotics. Beside complementing human labor artificial intelligence and robotics go further replacing it, and thus giving rise to unemployment (Ford 2015).Brendan Markey-Towler (2017) outlines that Robotics It is a substitute for the laborer himself and not merely some of his tasks. Recent empirical studies come with the idea that artificial intelligence and robotics may create wage gap between low skilled and high skilled labor (Krusell, Ohanian, Jose-Victor, Rios-Rull, and Giovanni. 2000). Tirole (2017) outlines that companies using artificial intelligence are more likely to deep this wage. In his work Cüneyt Diricanwor (2015) describes how lost of job and decreasing of wages will impact the economy through deflation. As laborers who are also viewed as customer will see their incomes cut this will lead to the decrease of demand thus affecting companies' revenues and profits. In contrast, the negative impact of artificial intelligence and robotics on employment is still discussed as rather then having substitute effect, machines and human labor could both be complementary (Erik Brynjolfsson \& Andrew Mcaffee.2014).Hanson (2001) shared the idea of complementary when analyzing the effect of machine intelligence on the economic growth. In the US for example the unemployment rate has been decreasing the last six years. Bao Chunlei found that the fast growing of artificial intelligence in China leads to the rise of new jobs. Acemoglu, Daron and Pascual Restrepo (2016) suggest a model in which Unemployment can be avoided by creating new task where human labor has more comparative advantage while former task are under Automation.

Likewise their impact on productivity and employment, artificial intelligence and robotics are thought to be key engines of entrepreneurship and innovation as we can witness the outsourcing of numbers of task toward new independent agents who will consequently construct their own reputation Tirole (2017). According to Bao Chunlei artificial intelligence is a driver of both innovation and entrepreneurship since it brings new products and services meanwhile leading to introduction of new businesses. But Aghion, Benjamin \& Charles (2017) point out that artificial intelligence may negatively affect innovation activities since it speeds up imitation.

\subsection{Big Data}

Large data is a data set with the main features of large capacity, large type, fast access speed and high application value, it is rapidly evolving into a new generation of information technologies and service modes that capture, store and relate data in large numbers, sources and formats, from which new knowledge can be discovered, new values created and new capabilities enhanced. Big data analytic has become a prior for organizations (Gartner. 2016) as in a report in 2014 OECD found that data driven innovation enhance productivity within an economy. Brynjolfsson et al. (2011) carried out a survey based on 179 enterprises and found that data driven decision making is a key driver of innovation within firms. Indeed the use of big data allows firms to analyze customer's actual trends and predict their future expectation. This will enhance innovative activities since will lead to the introduction of new product and services (Angela Byers, 2015).Still at the micro level, big data enhances information transparency and drives improvements and efficiency of the firm's management system and particularly the decision making one (Abbasi, A., Sarker, S., and Chiang.2016).Angela Byers explained how from the inside, organizations can use big data analytic to detect the deficient components and run them to efficiency. In their work, Oliver Müller, Maria Fay \& Jan vom Brocke (2018) carry out an econometric analysis of the relationship between big data analytic and firm performance. Their result suggests that big data analytic investments are responsible of up to 7 percent of firm productivity. This could justify the growing demand for business analytic (IDC. 2016).Likewise reports of Accenture in 2016 outlined the high efficiency of organizations using big data analytics. Earlier, James Manyika, Michael Chui, Brad Brown, Jacques Bughin, Richard Dobbs, Charles Roxburgh, and Angela Hung Byers (2011) pointed out that big data will drive innovation, productivity growth and increase competitiveness. They argue that big data brings value in five fields in the US. Retailer using big data could increase its operating margin by more than 60 percent. They found that in the health-care big data could generate nearly $\$ 300$ billion each year. They also found that the efficient use of big data can allow European governments to save up to $\$ 149$ billion. Angela Byers (2015)on her own stands that big data is a key engine for GDP growth as governments will not only save resources by tailoring populations needs through the use of big data, it will also allow countries economies to experience better effectiveness in manufacturing, health-care and many other public sectors. Measuring the impact of big data on the UK GDP growth, Peter Goodridge and Jonathan Haskel (2015) found that in 2012 big data accounted for $0.02 \%$ of growth in market sector value-added, predicting a contribution of $0.07 \%$ to $0.23 \%$ to the annual growth in the upcoming decade.

\subsection{The Internet of things}

In a report of GSMA(2015)the Internet of Things was defined as the concept of Multiple machines, devices and appliances connected to the Internet through multiple networks that a provide consumers and businesses with innovative new services". Internet of things exert tremendous positive impact on economic growth and efficiency 
through better control in production process, extension of product lifetime, cost reduction, improvement of products and services linkage, fast production of products and services (Robert B.Cohen.2016). Another idea is the economic and business rejuvenating effect of the Internet of things. Indeed at the firm micro level, the Internet of Things enables organizations to rethink and reorganize their business model leading them to more efficiency. This occurs within the whole value chain in units such supply chain, marketing, sales, and even after sale service. The Internet of Things comes along with the concept of time saving, cost saving and virtual closeness. The Internet of Things pushes firms toward better engagement with consumers, allowing them to anticipate consumer's future needs and come out with innovative products and services.

Analyzing the Internet of Things impact on nation GDP growth, James Manyika and Chales Roxburgh (2011) reported that in 2009internet accounted for 70\%of the global GDP, reminding that the contribution of internet to the global GDP was even bigger than the total GDP of some countries such Spain and Canada. With an average of $3.4 \%$ of GDP in developed nations, the internet percentage in the global GDP was higher than the ones of agriculture and utilities with respective percentages of $2.2 \%$ and $2.1 \%$. Focusing on the case of developing nations such Brazil and India the Internet of Things percentage in the GDP growth was 11 percent over the past five years. While some studies point out the reverse effect of the Internet of Things on jobs, the study goes further remind us of the French economy case where 1.2 million jobs has been created while 500000 others destroyed.

According to a study of Adam Thierer and Andrea Castillo (2015) the Internet of Things generates economic growth trough cost saving, Value creation and productivity in sectors such health agriculture, manufacturing security, energy, retail and resource extraction. Smart device monitoring and adaptation will raise $\$ 1.1$ trillion to $\$ 2.5$ trillion value in healthcare, $\$ 2.3$ to $\$ 11.6$ trillion in global manufacturing and $\$ 500$ billion to $\$ 757$ billion in energy and service over the next decade. The total global impact of the Internet of Things technologies could generate $\$ 2.7$ trillion to $\$ 14.4$ trillion in value by 2025 .

The Internet of Things could bring up to $7 \%$ to the 28 Europeans countries by 2025 especially through productivity and value redistribution to consumers. The Internet of Things value for the 28 countries could reach nearly 1 trillion Euro trough eight sectors: transportation 245 billion, health 235 billion, housing and hospitality 165billion, industry 160 billion, retail and wholesale 60 billion, utilities 30 billion, public administration 30,primary sectors 15 billions (Kearney.2015).A recent report from Accenture (2018) explains that analysis based on economic modeling has shown that at the macro level internet of things could foster china's global competitiveness and productivity with consistent evidence at the micro level, indeed within the 15 next years in the manufacturing sector the Internet of Things could add US\$196 billion value to the GDP.

\section{Methodology}

The overall share of the digital economy to nation growth is constituted of a direct effect via the accumulation of digital capital and the indirect effect measured by the diffusion of digital capital into the productive system. In other words the measurement takes into accounts both the weight of digital economy sectors in GDP and the contribution of the digital economy to economic growth. Coe-Rexecode has calculated the overall impact of the digital economy on growth, the sum of the direct effect (accumulation digital capital in the economy) and the indirect effect (gains productivity enabled by digital deployment).In this work, total revenues generated through the production and use of digital technologies are used as indicators for our independent variables and the GDP amount used as indicator for our dependant variable. Data was collected from the China Statistic bureau. In this study we run a simple regression analysis within each of our independent variables cloud computer, artificial intelligence, robotics, internet of things, big data and our independent variable gross domestic product. This task is performed in order to find out how cloud computer, artificial intelligence, robotics, the Internet of Things , big data individually affect the economic growth through GDP from 2013 to 2018. Our interpretation will thus be based on the consideration of T values, P values, R squared values, Adjusted R squared values and regression coefficient values. 


\section{Result}

Table 1: Regression analysis of Cloud Computing and GDP in China 2013-2018

- reg lngdp InCloudCom

\begin{tabular}{r|ccc} 
Source & SS & df & MS \\
\hline $\begin{array}{r}\text { Model } \\
\text { Residual }\end{array}$ & .13971859 & 1 & .13971859 \\
\hline .006247535 & 4 & .001561884 \\
\hline Total & .145966124 & 5 & .029193225
\end{tabular}

$\begin{array}{lrr}\text { Number of obs } & = \\ \text { F } 1, \quad 4) & = & 89.46 \\ \text { Prob }>\text { F } & = & 0.0007 \\ \text { R-squared } & = & 0.9572 \\ \text { Adj R-squared } & =0.9465 \\ \text { Root MSE } & = & .03952\end{array}$

\begin{tabular}{r|rrrrrr}
\hline Ingdp & Coef. & Std. Err. & $t$ & P>lt & [958 Conf. Interval] \\
\hline IncloudCom & .3174774 & .0335668 & 9.46 & 0.001 & .224281 & .4106739 \\
-cons & 11.55944 & .206237 & 56.05 & 0.000 & 10.98683 & 12.13204
\end{tabular}

Table 2: Regression analysis of Artificial Intelligence and GDP in China 2013-2018

reg lngdp InAI

\begin{tabular}{|c|c|c|c|c|c|c|c|}
\hline Source & ss & df & & MS & & \multirow{2}{*}{$\begin{array}{l}\text { Number of obs } \\
\text { F( } 1,\end{array}$} & \multirow{2}{*}{$\begin{array}{r}6 \\
237.62\end{array}$} \\
\hline & & & & & & & \\
\hline Model & .143549714 & 1 & \multicolumn{2}{|c|}{.143549714} & & Prob $>F$ & 0.0001 \\
\hline Residual & .00241641 & 4 & .00 & 604103 & & R-squared & 0.9834 \\
\hline Total & .145966124 & 5 & .02 & 193225 & & $\begin{array}{l}\text { Adj R-squared } \\
\text { Root MSE }\end{array}$ & .02458 \\
\hline lngdp & Coef. & Std. & Err. & $t$ & $P>|t|$ & [95\& Conf. & Interval] \\
\hline $\ln A I$ & .1638226 & .010 & 274 & 15.42 & 0.000 & .1343161 & .193329 \\
\hline _cons & 12.75312 & .0497 & 378 & 256.41 & 0.000 & 12.61502 & 12.89121 \\
\hline
\end{tabular}

Table 3: Regression analysis of Robotics and GDP in China 2013-2018

- reg Ingdp InRobotics

\begin{tabular}{|c|c|c|c|c|c|c|c|}
\hline Source & ss & df & \multicolumn{2}{|r|}{ MS } & & \multirow{2}{*}{$\begin{array}{l}\text { Number of obs } \\
\text { F ( } 1,\end{array}$} & 6 \\
\hline Mode1 & 141849726 & 1 & 14 & 849726 & & & $\begin{array}{l}=137.84 \\
=0.003\end{array}$ \\
\hline Residual & .004116399 & 4 & & 010291 & & R-squared & 0.9718 \\
\hline Total & .145966124 & 5 & .02 & 193225 & & $\begin{array}{l}\text { Ad] R-squared } \\
\text { Root MSE }\end{array}$ & $\begin{array}{l}0.9647 \\
.03208\end{array}$ \\
\hline Ingdp & Coef. & Std. & Exr. & $t$ & $P>|t|$ & [958 Conf. & Interval] \\
\hline InRobotics & .3506194 & .029 & 3642 & 11.74 & 0.000 & .2677032 & .4335356 \\
\hline _cons & 12.1537 & $.115^{\prime}$ & 1606 & 104.99 & 0.000 & 11.8323 & 12.47511 \\
\hline
\end{tabular}

Table 4: Regression analysis of Big Data and GDP in China 2013-2018

reg lngdp lnBigData

\begin{tabular}{r|ccc} 
Source & SS & df & MS \\
\hline $\begin{array}{r}\text { Model } \\
\text { Residual }\end{array}$ & $\begin{array}{r}.142780283 \\
.003185841\end{array}$ & $\begin{array}{l}1 \\
.142780283 \\
.00079646\end{array}$ \\
\hline Total & .145966124 & 5 & .029193225
\end{tabular}

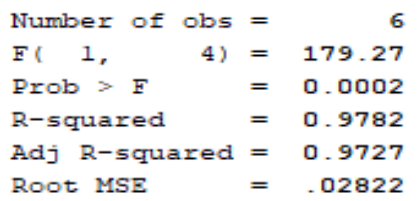

\begin{tabular}{|c|c|c|c|c|c|c|}
\hline lngdp & Coef. & Std. Err. & $t$ & $P>|t|$ & [958 Conf. & Interval] \\
\hline InBigData & .2632902 & .0196645 & 13.39 & 0.000 & .2086928 & .3178875 \\
\hline _cons & 12.2038 & .0977947 & 124.79 & 0.000 & 11.93227 & 12.47532 \\
\hline
\end{tabular}


Table 5: Regression analysis of the Internet of Things and GDP in China 2013-2018

reg lngdp InIoT

\begin{tabular}{r|ccc} 
Source & SS & df & MS \\
\hline $\begin{array}{r}\text { Model } \\
\text { Residual }\end{array}$ & $\begin{array}{l}.143754775 \\
.002211349\end{array}$ & $\begin{array}{l}\text { 4 } \\
.143754775 \\
.000552837\end{array}$ \\
\hline Total & .145966124 & 5 & .029193225
\end{tabular}

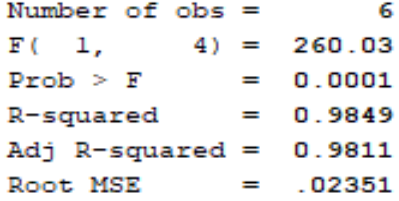

\begin{tabular}{r|rrrrrr}
\hline Ingdp & Coef. & Std. Brr. & $t$ & P > |t & [958 Conf. Interval] \\
\hline InIoI & .403119 & .0249989 & 16.13 & 0.000 & .3337109 & .4725271 \\
_cons & 9.85761 & .2263336 & 43.55 & 0.000 & 9.229208 & 10.48601
\end{tabular}

From the five tables we obtained R-squared values respectively equal to $0.95,0.98,0.97,0.97$ and 0.98 ; all representing a high power of explanation of the individual impact of cloud computing, artificial intelligence, robotics, big data and the Internet of Things on the variable GDP. Outputs from the five tables suggest that in China, digital technologies such as cloud computing, artificial intelligence, robotics, big data and the Internet of Things all positively affect the country GDP. Regressions of tables $2,3,4$ and 5 exhibit $P$ values all $=0.000$ while table 1 shows a $\mathrm{P}$ value $=0.001$ but still $<0.5$. Besides we have $\mathrm{T}$ values all $>$ than 2 , respectively $9.46,15.42$, 11.74, 13.39 and 16.13.Regarding these $\mathrm{T}$ and $\mathrm{P}$ values we tend to reject the null hypothesis $\mathrm{H}_{\mathrm{o}}$ and accept the alternative hypothesis $\mathrm{H}_{\mathrm{a}}$ in the five regression tables to say that cloud computing, artificial intelligence, robotics, big data and the Internet of Things all have positive impact on the GDP growth.

Analyzing the direction of the impacts of each digital technology on the GDP is one thing, but it is necessary to find the degree of significance of each of them. In fact, our analysis besides exhibiting the positive impact of digital technologies on the GDP reveals considerable differences in term of how far and how much. The coefficient values of each of the five tables give sight of these differences. In point of fact in China the Internet of Things is experiencing a fast widening, developing like a blowout affecting various business and economic activities, leading them to more effectiveness, performance and profitability. In China the Internet of Things has become a part of organization culture, in some industries further constitute a part of the corporate DNA. People and business and henceforth all connected making transactions and operations faster and larger than before. For example mobile payment transactions are growing to a great extend ranking first in the world with $\$ 12200$ billion value in 2016 . During the same year, accounting for $39.2 \%$ of global electronic transaction China's e-commerce transactions amounted to $\$ 3920$ billion with an average annual growth up to $30 \%$. Given all these table 5 shows the highest coefficient $=0.4031$, meaning that when the Internet of Things will increase by 1 unit then GDP will increase by 0.4031 .Robotics follows as the second digital technology having a higher degree of significance with its coefficient $=0.3506$. Our results also suggest that the third most significant digital technology in terms of impact on the GDP in China is the Cloud Computing since table 1 shows a coefficient $=0.3174$ implying that when an increase of one unit of cloud computing will give rise to an increase of 0.3174 of GDP.

Finally comes Big data and Artificial Intelligence with respectively 0.2632 and 0.1638 both representing the lowest degree of significance. The low degree of significance of Artificial Intelligence and its limited economic benefits for China compared to the four other digital technologies can be explained by some impediments. In fact in China the Artificial Intelligence field is encountering many challenges. The first challenge of AI effectiveness in China is related to the restraint access to data. As we know Artificial Intelligence needs data for its development, but China lacks data friendly ecosystem. Chinese government is characterized by communism, information and access data remains strictly under the central government control. Another fact is that China is building high restrictions on cross border data flows; this makes it hard for start-up to find their ways towards new competitive business and does not help to foster innovation in the private sector. Studies have also found that although china is standing at the first line in terms of Artificial Intelligence publications, these publications remains without influence. Finally, China Artificial Intelligence is undergoing talent shortage, indeed while in China up to 39\% of data scientists have less than 6 years experience, in the US half of them have up to 10 years experience.

\section{Conclusion}

This study aimed to analyze the impact of digital technologies on the Chinese Economic growth. A broad definition of the term digital technologies reveals limitations of existing research on the topic. While precedent studies focused on Information Technology to explain the economic importance of digital technologies for growth, our work considered a larger extend of the term including Cloud Computing, Artificial Intelligence, Robotics, Internet 
of Things and Big Data. The literature has shown that each of the five above digital technologies affects innovation, profitability and growth at the macro and micro level. Putting emphasis on the case of China, analysis based on six years 2013-2018 reveals that the share of digital economy in China's GDP is rapidly growing. The market size of the country's digital technologies are expanding and being applied to various business sectors and economic activities, making them to more effectiveness, performance and productivity. Despite the positive effect of Cloud Computing, Artificial Intelligence, Robotics, Internet of Things and Big Data on the Chinese GDP, we noted considerable differences among the fives digital technologies in term of their level of significance. The Internet of Things appearing as the digital technology having the most significant impact on the country GDP, followed by Robotics ,Cloud computing, Big Data and finally AI impacting the less compared to others. Despite the fast growing share of digital economy in the Chinese GDP we consider that efforts are still to be deployed for the country to gain more economic benefits from the emerging digital technologies. This will constitute the heart of our future debates and research as we also pose that wide range of digital technologies isolated on their own are not sufficient enough to boost innovation and profitability within organization, it's more about strategies, there comes the need for organization to leverage scheme and come out with appropriate digital transformation framework to adapt themselves in the new digital ecosystem.

\section{References}

Abbasi, A., Sarker, S., and Chiang, R. H. Big data research in information systems: Toward an inclusive research agenda. Journal of the Association for Information Systems, 17, 2 (February 2016)

Accenture. How the Internet of Things Can Drive Growth in China's industries. 2018 https://www.accenture.com/us-en/insight-how-the-internet-of-things-can-drive-growth-in-china-industries

Accenture. Winning with analytics.2016 www.accenture.com/usen/ / media/

Accenture/next-gen/hp-analytics/pdf/Accenture-Linking-Analytics-to-HighPerformance-ExecutiveSummary.pdf).

Acemoglu, Daronand Pascual Restrepo,"The Race between Man and Machine: Implications of Technology for Growth, Factor Shares and Employment,"May2016.

Adam Thierer and Andrea Castillo.Projecting the Growth and Economic Impact of the Internet of Things.15 June 2015

Aghion Philippe, Benjamin Jones and Charles 1.Jones (2017),"AI and Economic Growth," Economics of Artificial Intelligence

Angela Byers.Big data, Big economic impacts? I/S: A Journal of Law and Policy for the Information Society, vol. 10, no. 3 (2015), 757-764.

Azarnik A, Shayan J, Alizadeh M, Karamizadeh S. Associated Risks of Cloud Computing for SMEs. Open International Journal of Informatics. 2012; 1:37-45.

Bao Chunlei, China Institute of Labor and Social Security Sciences. Artificial Intelligence statement

Brynjolfsson, E., L. Hitt, et al. (2011). "Strength in Numbers: How Does Data-Driven Decision-making Affect Firm Performance?" Available at SSRN 1819486.

Brynjolfsson, E., \& McAfee, A. (2014). The second machine age: Work, progress, and prosperity in a time of brilliant technologies. WW Norton \& Company.

B. Markey-Towler. I, robotics economics. Cambridge Journal of Economics, 41(1):203-237, 2017. doi: 10.1093/cje/bew014.

C. Lawson. Technology and the extension of human capabilities. Journal for the Theory of Social Behaviour, 40(2):207-223, 2010.

M. Ford. Rise of the Robots. One world Publications, London, 2015.

Centre for economics and business research ltd. THE CLOUD DIVIDEND: Part One, The economic benefits of cloud computing to business and the wider EMEA economy, France, Germany, Italy, Spain and the UK. 2010.

Cüneyt Dirican, 2015, 'The Impacts of Robotics, Artificial Intelligence On Business and Economics', Procedia Social and Behavioral Sciences, vol. 195, pp. 564-573

Cockburn, Iain, Rebecca Henderson, and Scott Stern. 2017. "The Impact of Artificial Intelligence on Innovation." In The Economics of Artificial Intelligence, eds., Ajay Agrawal, Joshua S. Gans and Avi Goldfarb, Chicago: University of Chicago Press (forthcoming)

Etro F. The economic impact of cloud computing on business creation, employment and output in Europe. Review of Business and Economics. 2009; 54(2):179-208.

Filiopoulou, E., Mitropoulou, P. and Michalakelis, C. SMEs in the cloud: The impact of cloud adoption on economic growth and development. In Proceedings of the ICEIRD 2014 (Nicosia, Cyprus, 5-6 June, 2014).

Gartner. Magic Quadrant for Business Intelligence and Analytics Platforms. February 4, 2016 (available at www.gartner.com/doc/reprints?id=12XYY9ZR\&ct=160204 \&st=sb).

George Graetz and Guy Michaels: Estimating the impact of robots on productivity and employment .March 2015 
Griffith E. What Is Cloud Computing? Www.pcmag.com2013. Available from: http://www.pcmag.com/article2/0,2817,2372163,00.asp

GSMA: The Impact of the Internet of Things. The Connected Home, 26 March 2015. www.gsma.com/connectedliving

Hanson Robin(2001),"The Economic growth given machine intelligence,"Technical Report, University of California,Berkeley.

Han Qi .The influence of cloud computing on Chinas economic and social development and the countermeasures. $1671-6558(2015) 02-90-05$ doi :10. 3969/j. issn. 1671-6558. 2015. 02 . 023

IDC. Worldwide Big Data and Business Analytics Revenues Forecast to Reach \$187 Billion in 2019, According to IDC. Press release. May 23, 2016 (available at www.idc.com/getdoc.jsp?containerId=prUS41306516).

James Manyika and Chales Roxburgh.The great transformer: The impact of internet on economic growth and prosperity.October 2011

James Manyika, Michael Chui, Brad Brown, Jacques Bughin, Richard Dobbs, Charles Roxburgh, and Angela Hung Byers.Big data: The next frontier for innovation, competition, and productivity.McKinsey Global Institute - May 2011.

Jason Furman and Robert Seamans,"AI and the economy," Innovation Policy and the Economy. 2018. Volume 19 (2019): 161-191

John Hwaskworth, Richard Berriman and Saloni Goel: Will robots really steal our jobs? An international analysis of the potential long term impact of automation.2018

Judith H, Robin B, Marcia K, Fern H. Available from: http://www.dummies.com/how to/content/what-is-cloudcomputing.html. 2009

Kearney, A. T.(2015) The Internet of Things: A new path to European prosperity. Retrieved August 1, 2016, from https://www.atkearny.co.uk/communications-media-technology/-/asset_publisher/8Ru

TMUxXJpxX/content/the-internet-of-things-a-new-path-to-european-prosperity/10192

Konstantinos, Katsantonis \& Mitropoulou, Persefoni \& Filiopoulou, Evangelia \& Michalakelis, Christos \& Nikolaidou, Mara. (2015).Cloud computing and economic growth.10.1145/2801948.2802000.

Krusell, Per, Lee E Ohanian, and Giovanni L Violante, "Capital-skill complementarity and inequality: A macroeconomic analysis,” Econometrica, 2000, 68 (5), 1029-1053

Leila Serhan https://www.weforum.org/agenda/2015/05/how-cloud-technology-could-Boost-economic-growth

Marston, S., Li, Z., Bandyopadhyay, S., Zhang, J. and Ghalsasi. A. Cloud computing - the business perspective. Decision Support Systems, 51, 1 2011), 176-189.

McKinsey Global Institute. Artificial intelligence: Implications for China. April 2017

McKinsey Global Institute: China's future path of artificial intelligence.

Murphy, R. (2000). Introduction to AI robotics. MIT press.

OECD. Data-driven innovation for growth and well-being. Interim synthesis report. Paris: OECD Publishing, 2014.

Oliver Müller, Maria Fay \& Jan vom Brocke (2018) The Effect of Big Data and Analytics on Firm Performance: An Econometric Analysis Considering Industry Characteristics, Journal of Management Information Systems, 35:2, 488-509,DOI:10.1080/07421222.2018. 1451955

Peter Goodridge, Jonathan Haske. How does big data affect GDP? Theory and evidence for the UK. July 2015.

Coe-Rexecode, Digitization plays an essential role in growth, A new study on a highly strategic sector - May 2011, http://www.rexecode.fr/public/Presse/Communiques-de-presse/Digitization-plays-an-essential-role-ingrowth

Rich, E. (1985). Artificial intelligence and the humanities. Computers and the Humanities, 19(2), 117-122.

Robert B. Cohen. How IoT helps Firms Optimize Performance and IoT's future economic impact. IoT Global innovation Forum 2016.

Tirole, Jean, Economics for the Common Good, Princeton University Press, 2017. 